\title{
Prevalence and clinical relevance of the anatomical variations of suprarenal arteries: a review
}

\author{
Ananya Priya ${ }^{1}$, Ravi Kant Narayan ${ }^{2}$, Sanjib Kumar Ghosh ${ }^{1}$ \\ ${ }^{1}$ Department of Anatomy, All India Institute of Medical Science, Patna, ${ }^{2}$ Department of Anatomy, Andaman and Nicobar Islands Institute of Medical \\ Sciences, Port Blair, India
}

\begin{abstract}
The suprarenal arteries are arising from three sources: superior suprarenal artery, middle suprarenal artery, and inferior suprarenal artery. Variations in the arterial supply of the suprarenal glands in respect to origin and number are quite common and very frequently reported. The most common variation noted is in the inferior suprarenal artery followed by the middle suprarenal artery and the least common variations were observed in the superior suprarenal artery. Arteriogram of the inferior suprarenal artery is crucial in suprarenal tumour diagnosis but variation in the branching pattern and multiplicity of these arteries can cause hindrance in arteriography. The absence of middle suprarenal artery was seen to be associated with increased number of the inferior suprarenal artery. Variation in the multiplicity of arteries was observed more frequently in the inferior suprarenal artery and middle suprarenal artery which was more on the right side in most of the studies. Also, the variation in suprarenal arteries was often correlated to variations in inferior phrenic and gonadal arteries. The variations were observed to be more common on the left side therefore right adrenalectomy should be preferred over the left one. The loop formed by the inferior suprarenal artery around the right renal vein can cause venous obstruction. These variations of suprarenal vasculature are explained on the developmental basis, and prior knowledge of such variants is crucial for nephrologists to ensure minimum blood loss while performing laparoscopic adrenalectomy especially for large adrenal tumours and pheochromocytoma where the duration of surgery exceeds the usual.
\end{abstract}

Key words: Angiography, Inferior suprarenal arteries, Middle suprarenal arteries, Superior suprarenal arteries, Suprarenal gland

Received October 28, 2021; Revised November 23, 2021; Accepted November 23, 2021

\section{Introduction}

The suprarenal glands regulate a myriad of bodily functions such as metabolism, immune system, blood pressure, and response to stress via the hormones released. The corti-

\section{Corresponding author:}

Ananya Priya (iD)

Department of Anatomy, All India Institute of Medical Science, Patna, Bihar 801507, India

E-mail: ananyapriya@ymail.com cal and medullary secretions of the adrenal are released into the sinuses receiving one of the highest arterial flow rates per gram of tissue $(5-10 \mathrm{ml} / \mathrm{g} / \mathrm{min})[1]$. The abundant blood supply is received through numerous branches of the three different arteries, namely, superior suprarenal artery (SSA), middle suprarenal artery (MSA), and inferior suprarenal artery (ISA) (Fig. 1A). Mostly, the SSA arises from the ipsilateral inferior phrenic artery (IPA) and passes to the gland as four or five small branches. The MSA is usually single and arises from the lateral aspect of the abdominal aorta (AA) at around the level of the superior mesenteric artery (SMA). The ISA arises as one or two arteries from the ipsilateral re-

\section{Copyright ( 2022 . Anatomy \& Cell Biology}

This is an Open Access article distributed under the terms of the Creative Commons Attribution Non-Commercial License (http://creativecommons.org/licenses/by-nc/4.0/) which permits unrestricted non-commercial use, distribution, and reproduction in any medium, provided the original work is properly cited. 


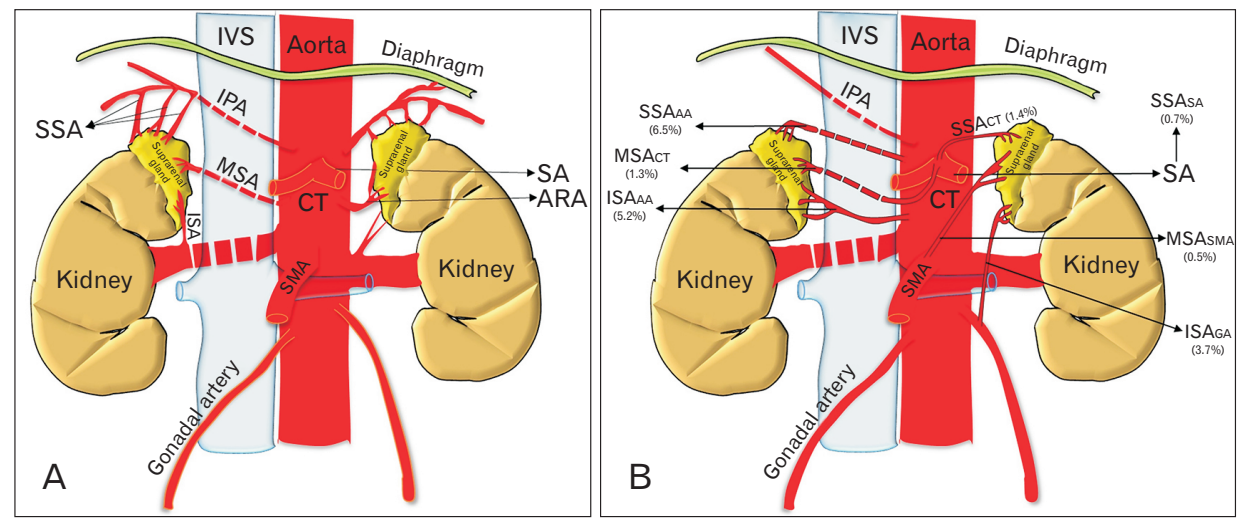

Fig. 1. Schematic diagram of arterial supply of suprarenal gland. (A) Shows normal arterial supply of the suprarenal gland. (B) Shows the most common variant origins of superior, middle, and inferior suprarenal arteries being reported. IVC, inferior vena cava; IPA, inferior phrenic artery; SSA, superior suprarenal artery; MSA, middle suprarenal artery; ISA, inferior suprarenal artery; SMA, superior mesenteric artery; CT, coeliac trunk; SA, splenic artery; ARA, accessory renal artery; $S_{S A}$, superior suprarenal artery originating from the abdominal aorta; MSA $_{\mathrm{CT}}$, middle suprarenal artery originating from the coeliac trunk; $\mathrm{ISA}_{\mathrm{AA}}$, inferior suprarenal artery originating from the abdominal aorta; $\mathrm{SSA}_{\mathrm{CT}}$, superior suprarenal artery originating from the coeliac trunk; $\mathrm{MSA}_{\mathrm{SMA}}$, middle suprarenal artery originating from superior mesenteric artery; $\mathrm{ISA}_{\mathrm{GA}}$, inferior suprarenal artery originating from gonadal artery.

nal artery (RA) and contributes to most of the arterial supply to the gland [2].

Variation in the arterial supply of the suprarenal glands is quite common and very frequently reported. Previous studies have been done utilizing cadavers, angiographic data from human adult and fetuses, and corrosion casts as study samples [3]. In the literature, the most common variation noted was in ISA followed by MSA, while the least common variations were observed in SSA. Variation in the multiplicity of arteries was observed more frequently in ISA and MSA of the right side [4]. The absence of MSA was observed to be associated with increased number of ISA. Furthermore, the variation in suprarenal arteries was often correlated to variations in inferior phrenic and gonadal arteries [5].

As the vascular variations are asymptomatic therefore, prior understanding of the aberrant branching pattern of suprarenal arteries is very crucial and helps nephrologists in making preoperative decisions while performing surgical procedures Also, vascular evaluation is essential for interventional radiologists in planning procedures of the subphrenic region keeping in mind the extrahepatic collateral arteries [5-7].

The variations of suprarenal arteries regarding their presence/absence, origin, and number were mostly reported as case presentations and very few as original studies. The scattered data required an overall presentation concerning the prevalence and clinical effects of such a common variation in human anatomy. Therefore, this review aims to condense all the data on variant anatomy of suprarenal arteries regarding its origin, number, and branching pattern, while emphasizing the possible etiology behind such variations making use of the literature available, such that this information can be used by nephrologists, radiologists to reduce inadvertent mortality in neonates as well as adults undergoing adrenal procedures.

\section{Materials and Methods}

The study was conducted in the Department of Anatomy at All India Institute of Medical Sciences, Patna, India between April 2021, and May 2021. The literature was searched extensively using the following indexed databases:

1. Google Scholar (Google, Inc., Mountain View, CA, USA)

2. Medline and PubMed (United States National Library of Medicine, Bethesda, MD, USA)

3. Embase (Ovid Technologies, Inc., New York, NY, USA)

4. Scopus (Elsevier, Amsterdam, The Netherlands)

5. Cochrane library

6. Science direct

The study was performed according to the guidelines of PRISMA (Preferred Reporting Items for Systematic Reviews and Meta-Analyses) for reporting reviews in epidemiology. The literature was searched taking into consideration the relevant terminologies related to the suprarenal vasculature. On that account, the terms such as "variation in the arterial 


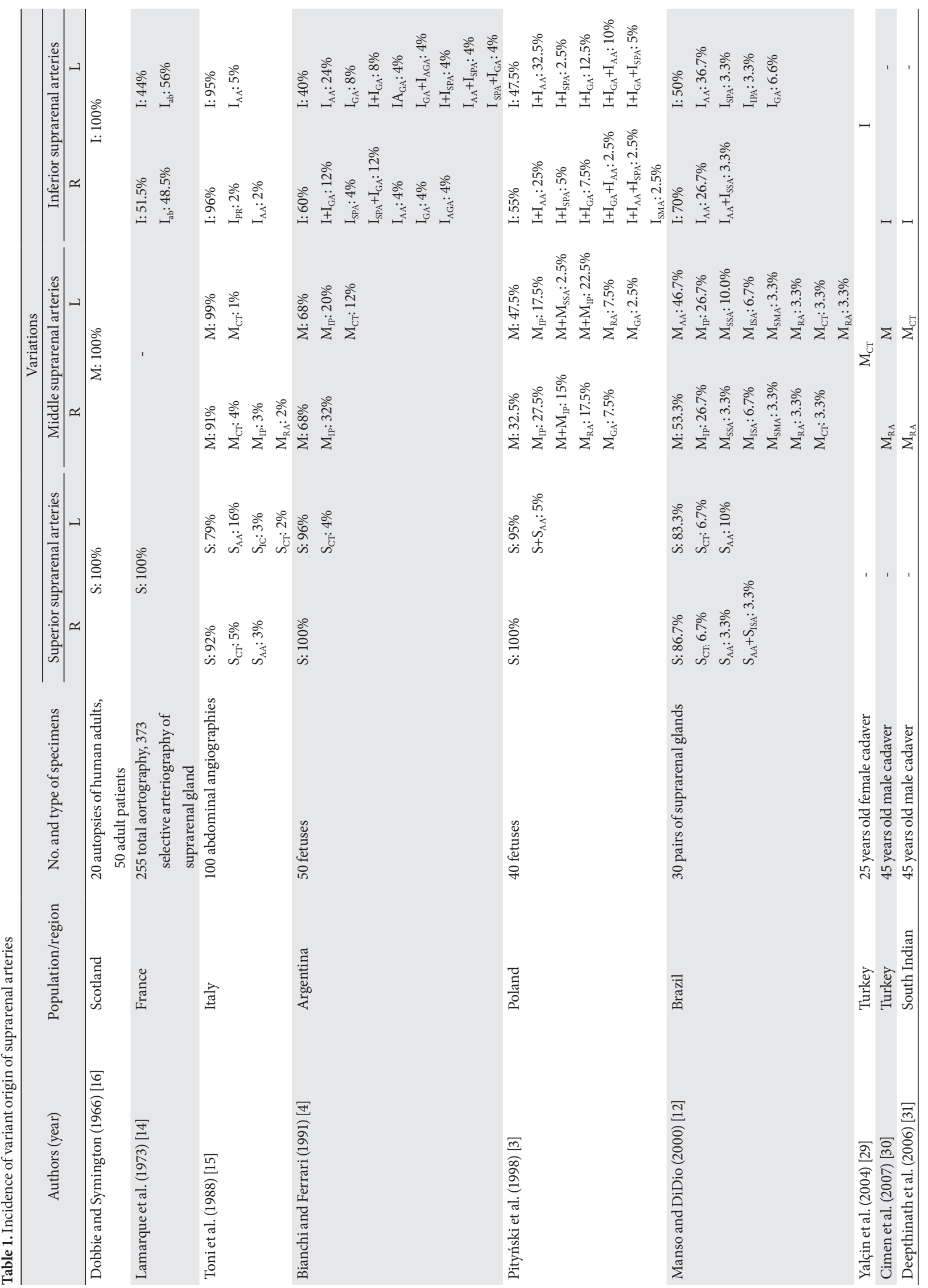




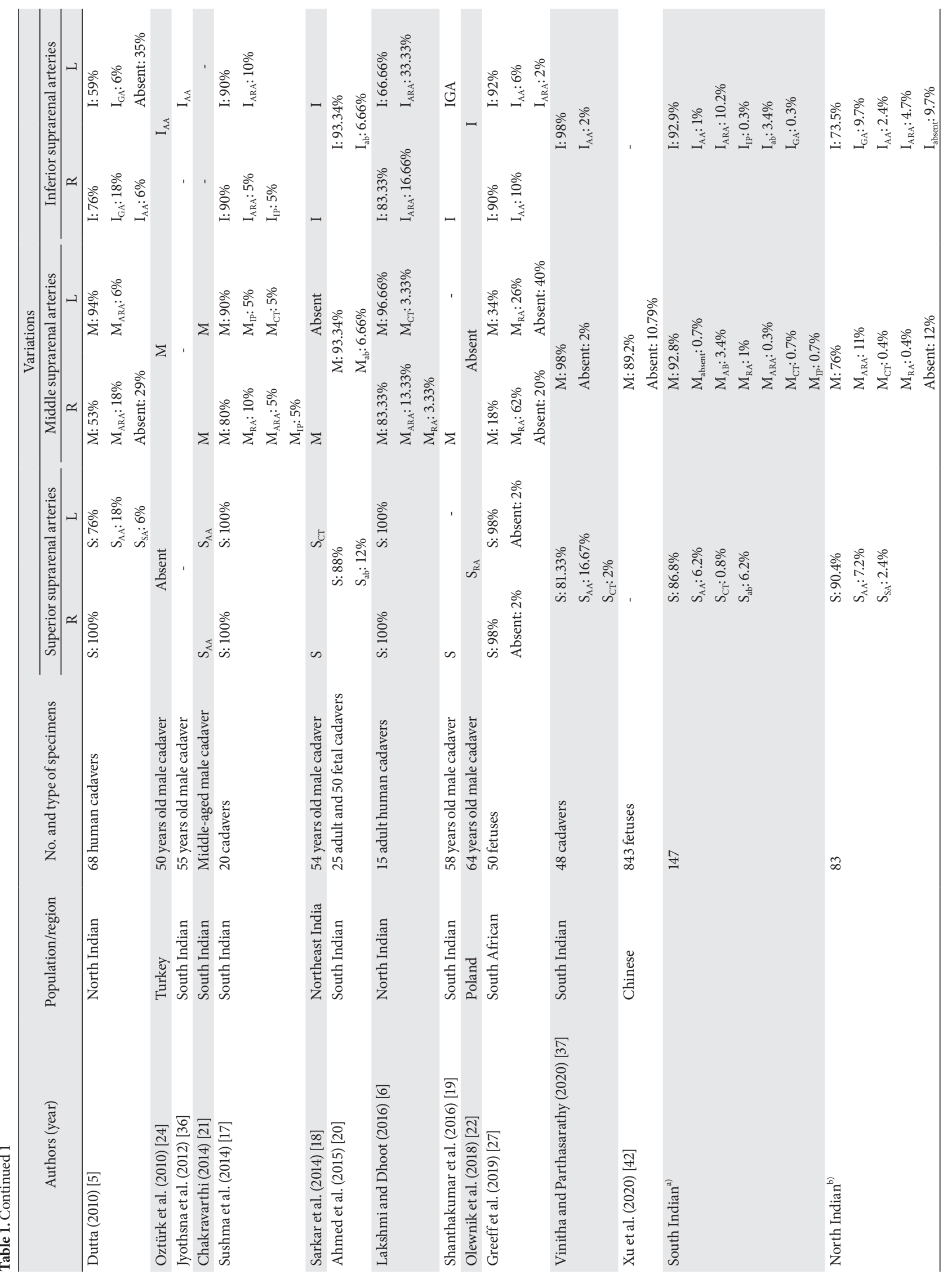




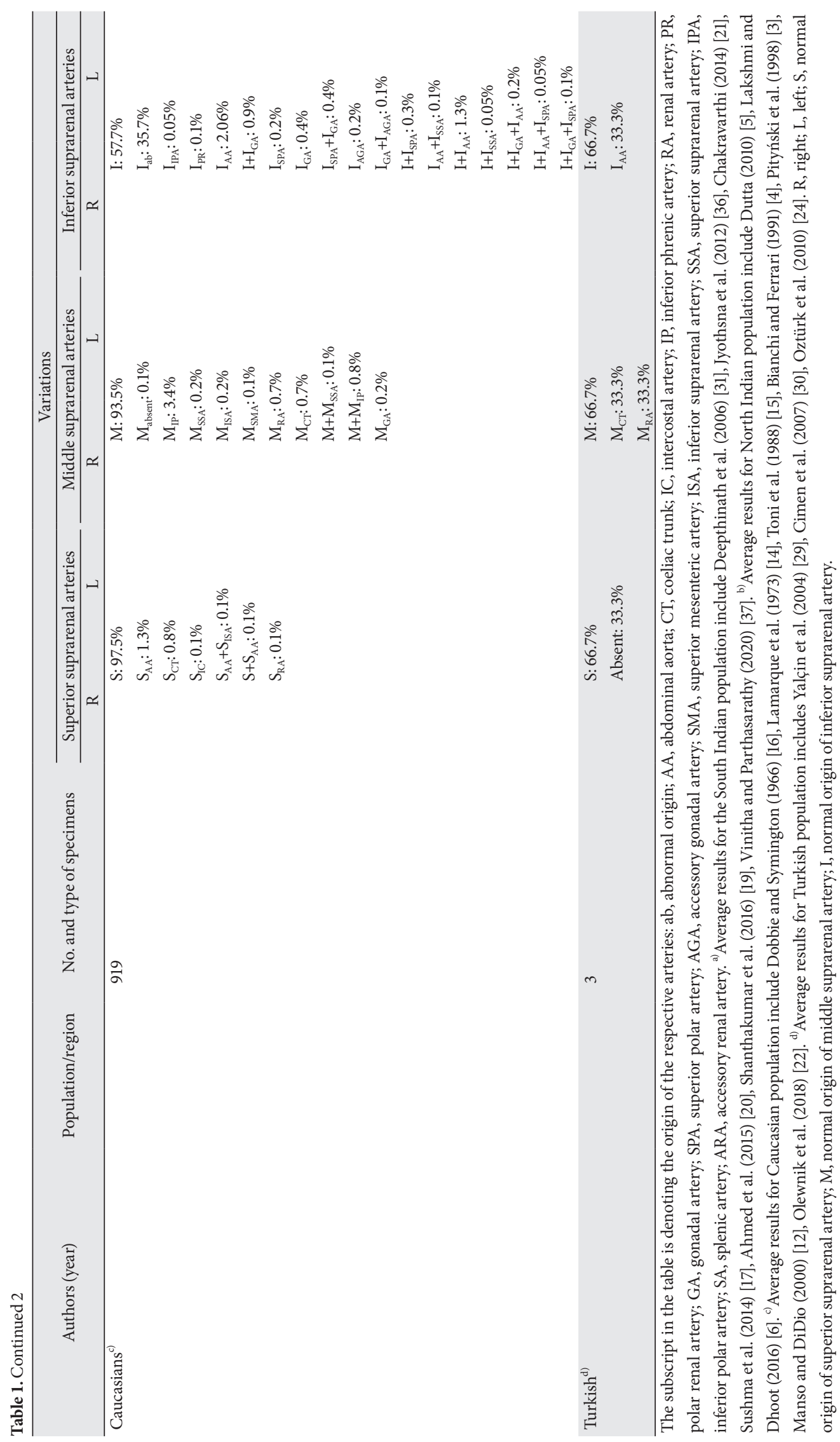


supply of suprarenal arteries, "unusual branching pattern of the middle suprarenal artery", "abnormal inferior suprarenal artery", "embryological basis of variation in the branching pattern of suprarenal arteries" were used in searching the literature. Only those studies were included which had significant data and information. The references from each study were analysed to look for other relevant studies which could be included. A blind literature search by all the authors was performed independently and the data was cumulated.

\section{Discussion}

According to the previous literature, the suprarenal glands were termed as "the adrenal glands" and therefore their vessels were known as "adrenal arteries or veins". Gagnon [8] suggested that the term "ad-renal" which means on the sides of the kidney is a misnomer and hence term "suprarenal" should be used based on the position of the glands (superior to the kidneys). According to the Federative Committee on Anatomical Terminology (FCAT) (1998) [9], the term "adrenal" was abolished, and then onwards their vessels were called the suprarenal arteries and veins. The suprarenal arteries were named according to their position of origin, as superior, middle, and inferior. This nomenclature was alternative to the ones proposed by Luna [10], who named the arteries based on their origin (i.e., aortic, renal, phrenic, and coeliac trunk). Paitre et al. [11] did a study to distinguish between main and accessory suprarenal arteries though it was not accepted [12].

Many authors of the early 90's worked on the variations of origin and number of the suprarenal arteries. Diard et al. [13] concluded that a major part of the gland was supplied by ISA (30\%-50\%), followed by SSA (30\%), and then MSA (20\%). Lamarque et al. [14] studied the bilateral difference in the blood supply of the suprarenal gland which was later confirmed angiographically by Toni et al. [15] (Table 1). With the increasing demand for suprarenal segmentectomy and transplantation as a treatment protocol of certain diseases, the knowledge regarding the origin and pattern of suprarenal arteries gained importance and therefore several studies

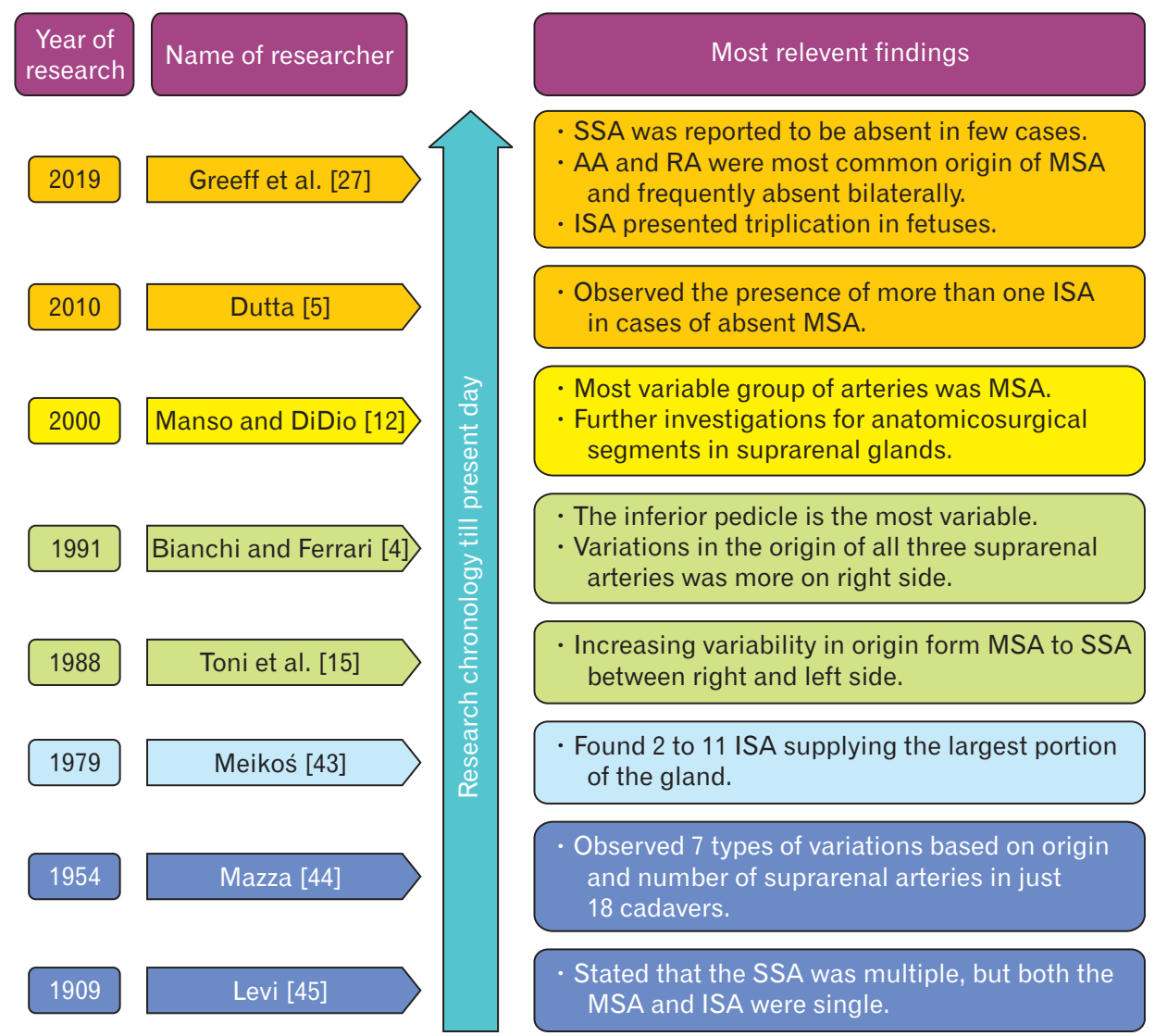

Fig. 2. A chronological illustration of hitherto most significant findings in the research history of arterial variations of suprarenal arteries. SSA, superior suprarenal artery; AA, abdominal aorta; RA, renal artery; MSA, middle suprarenal artery; ISA, inferior suprarenal artery. 
since then are being conducted using a variety of specimens such as adult human cadavers, dead fetuses, neonates, angiographic films, corrosion casts, and suprarenal gland obtained post-mortem. The research history of the variations of suprarenal arteries till date has been depicted in chronological order (Fig. 2).

\section{Variations of suprarenal arteries: with regards to the origin}

In most of the studies, the SSA had a normal origin on one or both the sides from the ipsilateral IPA which in turn branches out from AA above the coeliac trunk [3-6, 14, 1619]. Other studies and reports mentioned both normal and variant origin of the SSA. Ahmed et al. [20] reported a variant origin of SSA from AA either at or below the level of the coeliac trunk. They also noted the origin of SSA from two different sources in a single cadaver, one branch from IPA and the other from AA along with MSA. Chakravarthi [21] reported a case in which a common trunk from AA gave rise to the right and left superior suprarenal arteries along with right and left phrenic and left middle suprarenal arteries. Olewnik et al. [22] observed a variant origin of SSA from a common trunk along with right IPA and ISA from the right RA. Other than IPA, the SSA was observed to originate from AA and coeliac trunk (Fig. 1B) [3-5, 15, 23]. Very rarely SSA has also been reported to arise from splenic [5] and intercostal arteries (Table 1) [14].

The literature mentions the normal origin of MSA as a branch from either side of AA independently [16, 18, 21, 24]. Anupama et al. [25] reported a unique branching pattern for MSA, where it came out of a common trunk from AA along with the IPA, ISA, and left RA. Previously, a similar common trunk origin of MSA had been observed by Reddy et al. [26] where the right MSA and the right testicular artery branched out of the trunk from AA. The rare source of origin of MSA was reported from IPA, coeliac trunk, RA, gonadal artery, accessory renal artery, superior polar artery, and SSA (Table 1) [3-6, 15, 17, 23, 27]. Honma and Kudo [28] reported a unique origin of MSA from SMA unilaterally. The most-reported variation in the origin of MSA was from IPA and coeliac trunk (Table 1). Among all the three suprarenal arteries MSA was documented to be absent most frequently. Greeff et al. [27] had reported a bilateral absence of MSA in as much as $20 \%$ of the studied fetal samples, and another $20 \%$ samples had unilateral absent MSA. These absent MSA samples were observed to have extensive branching of ISA
(Table 1). It was noted that the missing MSA was more on the left side therefore in contrast to Manso and DiDio [12], the right adrenalectomy should be preferred over the left one.

As compared to MSA, in very few studies ISA was found to be absent. The present review observed that among the three suprarenal arteries, ISA had the most varied origins on either side, irrespective of the studied population (North/ South Indian, Caucasian, or Turkish). Only Dobbie and Symington's [16] study and the individual case report from Yalçin

Table 2. Comprehensive percentage variations of suprarenal arteries in different cadaveric, fetal, and angiographic studies

\begin{tabular}{|c|c|c|c|}
\hline \multirow{2}{*}{ Study type } & \multicolumn{3}{|c|}{$\%$ of common variations in origin } \\
\hline & SSA & MSA & ISA \\
\hline \multirow[t]{9}{*}{ Adult $(n=260)$} & S: 90 & M: 83 & I: 84 \\
\hline & $\mathrm{S}_{\mathrm{AA}}: 6.5$ & $\mathrm{M}_{\text {absent }}: 4.9$ & $\mathrm{I}_{\mathrm{AA}}: 5.2$ \\
\hline & $\mathrm{S}_{\mathrm{CT}}: 1.5$ & $\mathrm{M}_{\mathrm{ARA}}: 3.8$ & $\mathrm{I}_{\mathrm{GA}}: 3.6$ \\
\hline & $\mathrm{S}_{\mathrm{SA}}: 0.7$ & $\mathrm{M}_{\mathrm{IP}}: 3.5$ & $I_{\text {absent }}: 3.0$ \\
\hline & $\mathrm{S}_{\mathrm{RA}}: 0.4$ & $\mathrm{M}_{\mathrm{CT}}: 1.3$ & $\mathrm{I}_{\mathrm{ARA}}: 2.3$ \\
\hline & $\mathrm{S}_{\text {absent }}: 0.4$ & $\mathrm{M}_{\mathrm{RA}}: 1.3$ & $\mathrm{I}_{\mathrm{SPA}}: 0.2$ \\
\hline & $\mathrm{S}_{\mathrm{AA}}+\mathrm{S}_{\mathrm{ISA}}: 0.4$ & $\mathrm{M}_{\mathrm{SSA}}: 0.8$ & $\mathrm{I}_{\mathrm{IPA}}: 0.2$ \\
\hline & & $\mathrm{M}_{\mathrm{ISA}}: 0.8$ & $\mathrm{I}_{\mathrm{IP}}: 0.2$ \\
\hline & & $\mathrm{M}_{\mathrm{SMA}}: 0.5$ & $\mathrm{I}_{\mathrm{AA}}+\mathrm{I}_{\mathrm{SSA}}: 0.4$ \\
\hline \multirow[t]{15}{*}{ Fetal $(n=983)$} & S: 99.6 & $\mathrm{M}: 83$ & I: 94.9 \\
\hline & $\mathrm{S}+\mathrm{S}_{\mathrm{AA}}: 0.3$ & $\mathrm{M}_{\mathrm{absent}}: 10.9$ & $\mathrm{I}+\mathrm{I}_{\mathrm{GA}}: 0.9$ \\
\hline & $\mathrm{S}_{\mathrm{CT}}: 0.1$ & $\mathrm{M}_{\mathrm{RA}}: 2.8$ & $\mathrm{I}_{\mathrm{SPA}}+\mathrm{I}_{\mathrm{GA}}: 0.4$ \\
\hline & $\mathrm{S}_{\text {absent }}: 0.1$ & $\mathrm{M}_{\mathrm{IP}}: 2.3$ & $\mathrm{I}_{\mathrm{GA}}: 0.3$ \\
\hline & & $\mathrm{M}+\mathrm{M}_{\mathrm{IP}}: 0.7$ & $\mathrm{I}+\mathrm{I}_{\mathrm{SPA}}: 0.3$ \\
\hline & & $\mathrm{M}_{\mathrm{CT}}: 0.3$ & $\mathrm{I}+\mathrm{I}_{\mathrm{AA}}: 1.2$ \\
\hline & & $\mathrm{M}_{\mathrm{GA}}: 0.2$ & $\mathrm{I}_{\mathrm{AA}}: 1.1$ \\
\hline & & $\mathrm{M}+\mathrm{M}_{\mathrm{SSA}}: 0.1$ & $\mathrm{I}_{\mathrm{AGA}}: 0.2$ \\
\hline & & & $\mathrm{I}+\mathrm{I}_{\mathrm{GA}}+\mathrm{I}_{\mathrm{AA}}: 0.2$ \\
\hline & & & $\mathrm{I}_{\mathrm{SPA}}: 0.1$ \\
\hline & & & $\mathrm{I}_{\mathrm{ARA}}: 0.1$ \\
\hline & & & $\mathrm{I}_{\mathrm{GA}}+\mathrm{I}_{\mathrm{AGA}}: 0.1$ \\
\hline & & & $\mathrm{I}_{\mathrm{AA}}+\mathrm{I}_{\mathrm{SPA}}: 0.1$ \\
\hline & & & $\mathrm{I}+\mathrm{I}_{\mathrm{GA}}+\mathrm{I}_{\mathrm{SPA}}: 0.1$ \\
\hline & & & $\mathrm{I}+\mathrm{I}_{\mathrm{AA}}+\mathrm{I}_{\mathrm{SPA}}: 0.05$ \\
\hline \multirow[t]{2}{*}{ Adult+fetal $(n=75)$} & S: 88 & M: 93.3 & I: 93.3 \\
\hline & $\mathrm{S}_{\mathrm{AB}}: 12$ & $\mathrm{M}_{\mathrm{AB}}: 6.7$ & $\mathrm{I}_{\mathrm{AB}}: 6.7$ \\
\hline \multirow[t]{4}{*}{ Angiographic $(n=728)$} & S: 98 & M: 99.3 & I: 54.4 \\
\hline & $\mathrm{S}_{\mathrm{CT}}: 0.5$ & $\mathrm{M}_{\mathrm{CT}}: 0.5$ & $\mathrm{I}_{\mathrm{AB}}: 45$ \\
\hline & $\mathrm{S}_{\mathrm{AA}}: 1.3$ & $\mathrm{M}_{\mathrm{IP}}: 0.1$ & $\mathrm{I}_{\mathrm{PR}}: 0.2$ \\
\hline & $\mathrm{S}_{\mathrm{IC}}: 0.1$ & $\mathrm{M}_{\mathrm{RA}}: 0.1$ & $\mathrm{I}_{\mathrm{AA}}: 0.4$ \\
\hline
\end{tabular}

The subscript in the table is denoting the origin of the respective arteries: $a b$, abnormal origin; AA, abdominal aorta; CT, coeliac trunk; IC, intercostal artery; IP, inferior phrenic artery; RA, renal artery; PR, polar renal artery; GA, gonadal artery; SPA, superior polar artery; AGA, accessory gonadal artery; SMA, superior mesenteric artery; ISA, inferior suprarenal artery; SSA, superior suprarenal artery; IPA, inferior polar artery; SA, splenic artery; ARA, accessory renal artery. 
et al. [29] were the one to observe bilateral normal origin of ISA from the respective renal arteries. Though the unilateral normal origin of ISA was reported but that too in a few case reports [17, 18, 21, 29-31]. Bakheit and Motabagani [32] reported bilateral variation of ISA in a single cadaver where right ISA was given by IPA and the left one by the accessory renal artery. Some individual case reports noted the unilateral abnormal origin of ISA from the ipsilateral gonadal artery $[33,34]$, which coincided with the abdominal angiographic study done by Suoranta and Pietilä [35]. Subsequently, ISA was most commonly observed to have a variant origin from AA $[3,5,12,15,24,27,36,37]$, followed by gonadal artery [3-5, 12, 19], and accessory renal artery [6, 17, 23, 27] (Fig. 1B). Rarely, the variant origin of ISA was reported from the coeliac trunk [38], accessory gonadal artery [4], SMA [3], IPA, and SSA [12]. Lamarque et al. [14] and Hureau et al. [39] described the renal origin of ISA to be more frequent on the right side (Table 1).

After calculating the average region-wise percentage of the variations of suprarenal arteries it was observed that the most common variant origin of SSA was from AA irrespective of the region. The variant origin of MSA was observed to exhibit regional as well as population-based disparity. In the southern part of India, the most common variant origin of MSA was from the IPA, whereas in North Indian studies it was noted to arise from the accessory renal artery. In the Caucasian and Turkish populations, the MSA arose most commonly from the coeliac trunk. Substantial racial differences were found concerning the aberrant origin of ISA (Table 1). Comprehensive percentage of mode of origin of suprarenal arteries in cadaveric, fetal, and angiographic studies has also been calculated (Table 2).

Hagopian [40] described a case in which ISA arose from the testicular artery just caudal to the right renal vein and then ascended upwards anterior to the vein to supply the suprarenal gland in such a way that it forms a loop around the right renal vein. This arterial loop around the right renal vein can obstruct the right renal vein, the chances of which increase in case of nephroptosis (floating kidney).

\section{Variations of superior suprarenal artery: with regards to the number of arteries}

Rossi et al. [41] observed the maximum number of SSA in an individual to be 60, while Toni et al. [15] stated that the number of arteries reduced with age due to involution. Recent literature reports that SSA can branch profusely, such that their number could range from 1 to 30 from one or more sources (Table 3) [3, 12, 42]. In addition, the commonest branching pattern in most studies was reported as 4 to 8 arteries [3, 4, 12, 43-45]. On dissecting the fetal specimens, few authors concluded after that the number of MSA ranges mostly between 1 to $3[3,4]$. After analyzing the literature, it was observed that whenever two or more branches of MSA existed they came from different sources $[3,12]$. As far as ISA is concerned, a maximum of 5 branches were recorded in a fetal study [3].

\section{Clinical importance}

Awareness of variations in angioarchitecture of the suprarenal gland is beneficial while doing radiological and surgical procedures in the subphrenic region concerning the presence of extrahepatic collateral arteries formed, which often involves IPA and therefore the SSA. These variations can pose difficulties such as massive intraoperative haemorrhage during renal or suprarenal transplant, and in suprarenal segmentectomy by injuring the variant vessels unknowingly. ISA arteriogram is crucial in suprarenal tumour diagnosis but variations in the branching pattern and multiplicity of these arteries can cause hindrance in arteriography.

\section{Embryology}

Developmentally, the lateral splanchnic branches from the dorsal aorta are dedicated to supplying the kidneys, gonads, and suprarenal glands. Felix [46] gave the "Ladder Theory" and proposed that there are nine lateral splanchnic branches that normally disappear in caudal direction thus leaving behind cranial, middle, and caudal groups of arteries. The caudal group of arteries consists of fifth and sixth arteries on the right side and sixth to ninth arteries on the left side. The fifth to ninth arteries form an arterial network called "rete arteriosum urogenitale" which supplies the metanephros and suprarenal gland. The persistence of these arteries in certain circumstances leads to anomalous origin and number of suprarenal arteries, since all the arteries arise from this common network. Though Felix's "Ladder Theory" was widely accepted as it gave a simple explanation of variations of arterial supply of the suprarenal gland, he failed to emphasize the intermediate stage of changes in mesonephric arteries during the ascent of kidney.

An alternate theory for the abdominal vascular development was given by Hochstetter [47] in 1893, which mentions of a new direct branch to suprarenal gland and kidney from 


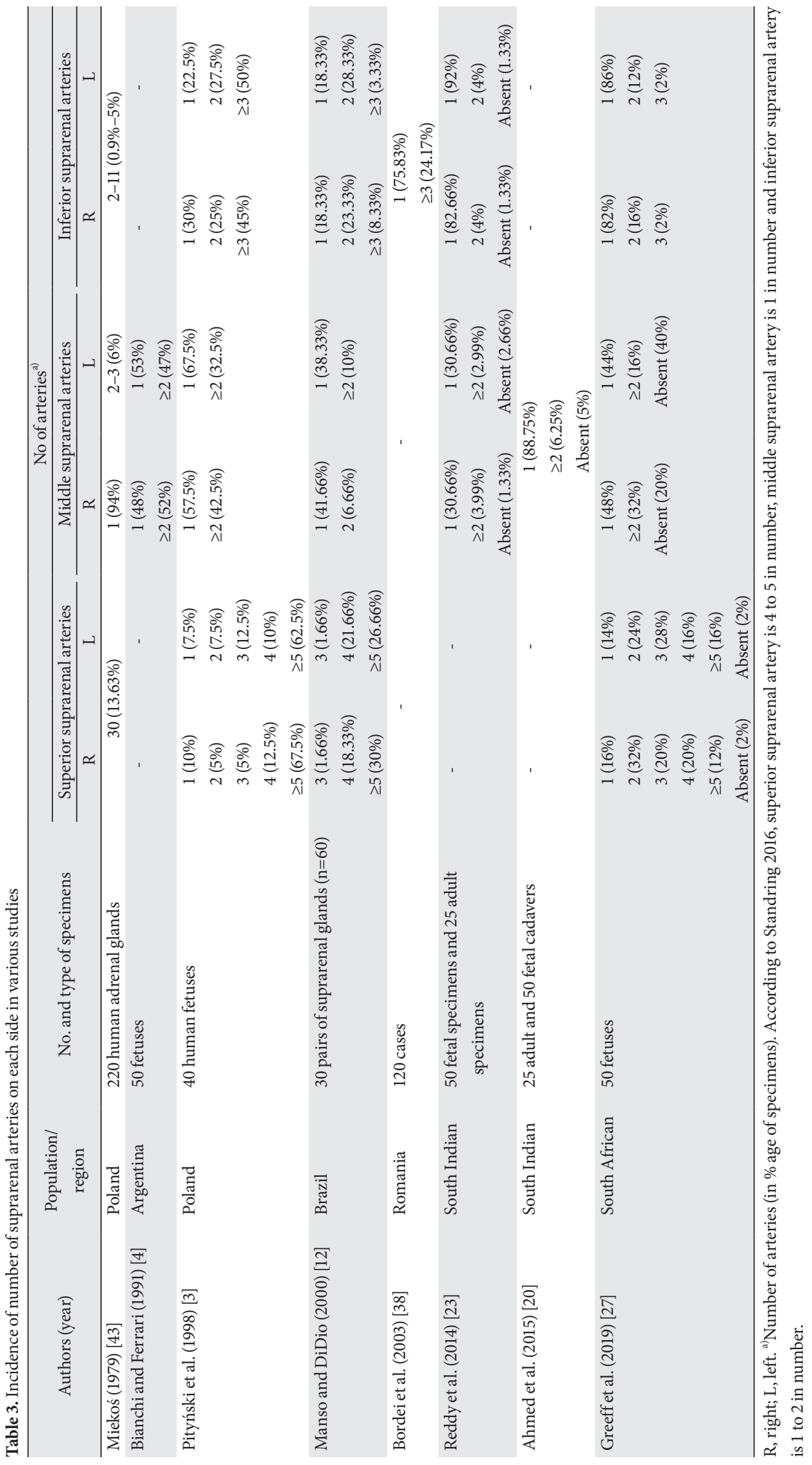


AA after they reach their destined vertebral level during development. Supportive evidence was presented by Abe [48] and Salama et al. [49] in hamsters and humans, but the lack of morphogenetic process display became the hurdle for them.

The 21st century reports by Isogai et al. [50] and Hinata et al. [51] presented evidence in support of Hochstetter theory. Isogai et al. [50] observed the emergence of new branches from the AA or gonadal artery in their rat embryo model. These new branches would become the renal or suprarenal arteries. They noted the obliteration of the mesonephric arteries before the metanephros reached the destined level. Hinata et al. [51] also presented similar evidence in their paraffin sections of the human embryo. The two studies observed variations in branching pattern or number of branches or both, in their respective models, but didn't provide an evidentiary proof or explanation for the same. Though Isogai et al. [50] suggested the trophic role of sympathetic nerve tissue in vascular development, it was being contradicted by Hinata et al. [51] who observed that the mesonephric arteries cross the nerves at the right angle, had there been any stimulation then some of the vessels should have followed the nerves. Then again, Hinata et al. [51] did mention that a vascular induction by the sympathetic component of suprarenal gland is more likely. Anyhow, an explanation regarding the vascular variations is yet to be established.

A possible explanation for these variations could be asserted by the findings of Turyna et al. [52] who explained the formation of aberrant renal arteries from secondary buddings on the AA wall and not from the pre-existing mesonephric arteries. They reported the finding of numerous retroperitoneal twigs from the aorta after the mesonephric arteries were obliterated. These retroperitoneal twigs might explain the variations in the branching pattern of the suprarenal artery from the aorta, but still, numerous findings couldn't be explained.

The suprarenal gland is derived from the para-aortic ridge or urogenital ridge. This para-aortic ridge also gives rise to hematopoietic stem cells which induce new branching from the aorta later in life [50]. The formation of blood vessels occurs due to vasculogenesis which is instead controlled by several signal molecules like VEGF, FGF, PECAM-1, and transcription factors like its-1 [53, 54]. Any defect in the gradient of these molecules leads to the aforesaid variations. Several other factors explain these variations: defect in intussusceptive arborization, a new stimulus for growth in surrounding mesoderm, or division of vessels by transendo- thelial bridges [55].

The variations in suprarenal arteries are commonly reported, but an embryological theory explaining these variations is yet to be established. The data presented in this study is in accordance with the published literature. The authors did not attempt to provide any specific clinical advice in this aspect. Hence, analytical interpretation from a clinical perspective is suggested in this regard. Future direction on this topic of research is that the research should be multicentric and must include a large sample size with real-time clinical data to comprehend the horizon of variations of arterial supply of suprarenal glands with a broader perspective.

\section{Conclusion}

The study provides the conclusion that among the three suprarenal arteries, ISA is the most common to have a variant origin (from AA, coeliac trunk, gonadal artery, or accessory renal artery), and that the MSA is the most common to be found absent. The variations were observed to be more common on the left side therefore right adrenalectomy should be preferred over the left one. The loop formed by the ISA around the right renal vein can obstruct the renal vein. The heterogeneity of data observed in the literature is due to ethnic and provincial disparities. The "ladder theory" was most accepted as it gave an easy embryological explanation to the variations of suprarenal arteries, but few recent studies disagreed with the theory and said that the persistence of mesonephric arteries is not responsible for these variations as they disappear much before the ascent of the kidney has started. The lack of an established embryological model explaining the variations provide further scope of research on the topic. The present review tabulates and analyses the available data on the variations of suprarenal arteries. This strengthens the database which provides essential information to instill awareness among the concerned clinicians regarding the possibilities of vascular variation related to suprarenal arteries.

\section{ORCID}

Ananya Priya: https://orcid.org/0000-0003-2787-1052

Ravi Kant Narayan:

https://orcid.org/0000-0003-2510-6744

Sanjib Kumar Ghosh:

https://orcid.org/0000-0002-7293-6735 


\section{Author Contributions}

Conceptualization: AP, RKN, SKG. Data acquisition: AP, RKN, SKG. Data analysis or interpretation: AP, RKN, SKG. Drafting of the manuscript: AP, RKN, SKG. Critical revision of the manuscript: AP, RKN, SKG. Approval of the final version of the manuscript: all authors.

\section{Conflicts of Interest}

No potential conflict of interest relevant to this article was reported.

\section{Acknowledgements}

We are grateful to all the residents and faculty members of All India Institute of Medical Sciences, Patna for their help and co-operation during the preparation of this manuscript.

\section{References}

1. Williams LR, Leggett RW. Reference values for resting blood flow to organs of man. Clin Phys Physiol Meas 1989;10:187-217.

2. Perrier ND. Suprarenal gland. In: Standring S, editor. Gray's Anatomy: The Anatomical Basis of Clinical Practice. 41st ed. London: Elsevier; 2016. p.1194-8.

3. Pityński K, Skawina A, Polakiewicz J, Walocha J. Extraorganic vascular system of adrenal glands in human fetuses. Ann Anat 1998;180:361-8.

4. Bianchi H, Ferrari A. The arterial circulation of the left suprarenal gland. Surg Radiol Anat 1991;13:113-6.

5. Dutta S. Suprarenal gland-arterial supply: an embryological basis and applied importance. Rom J Morphol Embryol 2010;51:137-40.

6. Lakshmi KV, Dhoot M. A study on the variations of arterial supply to adrenal gland. Int J Biomed Adv Res 2016;7:373-5.

7. Ahmadpour S, Foghi K. Multiple absences of the branches of abdominal aorta with congenital absence of the portal vein, unilateral adrenal agenesis and persistent ductus arteriosus in a female cadaver. Anat Cell Biol 2014;47:274-8.

8. Gagnon R. The arterial supply of the human adrenal gland. Rev Can Biol 1957;16:421-33.

9. Federative Committee on Anatomical Terminology. Terminologia anatomica: international anatomical terminology. Stuttgart: Thieme; 1998.

10. Luna E. [On the classification of adrenal arteries]. Mon Zool Ital 1909;20:290-5. Italian.

11. Paitre F, Dupret S, Giraud D. [Illusional anatomosurgical practice. Fasc III- retroperitoneal organisations]. Barcelona: Salvat Editores; 1941. Spanish.
12. Manso JC, DiDio LJ. Anatomical variations of the human suprarenal arteries. Ann Anat 2000;182:483-8.

13. Diard F, Levot J, Tavernier J. [Adrenal arteriography]. Bord Med 1972;5:1435-48. French.

14. Lamarque JL, Jaspart W, Delylle A, Senac JP. [Angiographic radio-anatomy of the adrenals]. Ann Radiol (Paris) 1973;16:54963. French.

15. Toni R, Mosca S, Favero L, Ricci S, Roversi R, Toni G, Vezzadini P. Clinical anatomy of the suprarenal arteries: a quantitative approach by aortography. Surg Radiol Anat 1988;10:297-302.

16. Dobbie JW, Symington T. The human adrenal gland with special reference to the vasculature. J Endocrinol 1966;34:479-89.

17. Sushma RK, Dhoot M, Harode HA, D’Souza AS, Mamatha H. Anatomical variations in the arterial supply of the suprarenal gland. Int J Health Sci Res 2014;4:31-6.

18. Sarkar M, Mukherjee P, Roy H, Sengupta SK, Sarkar AN. An unusual branch of celiac trunk feeding suprarenal gland - a case report. J Clin Diagn Res 2014;8:AD03-4.

19. Shanthakumar RS, Kumar N, Badagabettu SN, Kappettu Gadahad MR, Reghunathan D, Patil J. Rare combined variation of left suprarenal vessels associated with retroaortic left renal vein. Proc Singap Healthc 2016;25:112-4.

20. Ahmed MM, Reddy MV, Suresh S, Naaz A. The mystery around suprarenal gland- dispelled! IOSR J Dent Med Sci 2015;14:12-9.

21. Chakravarthi KK. Unilateral multiple variations of renal, phrenic, suprarenal, inferior mesenteric and gonadal arteries. J Nat Sci Biol Med 2014;5:173-5.

22. Olewnik $€$, Waśniewska A, Polguj M, Topol M. Rare combined variations of renal, suprarenal, phrenic and accessory hepatic arteries. Surg Radiol Anat 2018;40:743-8.

23. Reddy MV, Ahmed MM, Kumar PP, Raghuramaiah G. A study on vasculature of the suprarenal glands. Int J Anat Res 2014;2:195-201.

24. Oztürk NC, Uzmansel D, Kara A, Oztürk H. Variation in the position, relation and vasculature of left suprarenal gland: a case report. Surg Radiol Anat 2010;32:985-8.

25. Anupama D, Prabha Subhash RL, Suresh BS. Inferior phrenic artery, variations in origin and clinical implications- a case study. IOSR J Dent Med Sci 2013;7:46-8.

26. Reddy S, Bhat SM, Mathew JG, Shetty PC, Gorantla VR, Jetti $\mathrm{R}$, Vollala VR. A common trunk of origin of the right testicular and middle suprarenal arteries with a retrocaval course. Indian J Surg 2011;73:314-5.

27. Greeff B, Pillay P, De Gama BZ, Satyapal KS. An anatomical investigation of the vascular supply of the suprarenal glands in fetuses. Int J Morphol 2019;37:1023-32.

28. Honma S, Kudo M. The middle suprarenal artery arising from the superior mesenteric artery. Surg Radiol Anat 2012;34:93-5.

29. Yalçin B, Kocabiyik N, Yazar F, Ozan H, Özdoğmuş Ö. Variations of the branches of the celiac trunk. Gülhane Tip Dergisi 2004;46:163-5.

30. Cimen M, Erdil FH, Koşar MI, Sabancioğullari V. A rare variation of the right middle suprarenal artery. Ann Anat 2007;189:287-9. 
31. Deepthinath R, Satheesha Nayak B, Mehta RB, Bhat S, Rodrigues V, Samuel VP, Venkataramana V, Prasad AM. Multiple variations in the paired arteries of the abdominal aorta. Clin Anat 2006;19:566-8.

32. Bakheit MA, Motabagani MA. Anomalies of the renal, phrenic and suprarenal arteries: case report. East Afr Med J 2003;80:497-8.

33. Brohi RA, Sargon MF, Yener N. High origin and unusual suprarenal branch of a testicular artery. Surg Radiol Anat 2001;23:2078.

34. Nayak SR, J JP, D’Costa S, Prabhu LV, Krishnamurthy A, Pai MM, Prakash. Multiple anomalies involving testicular and suprarenal arteries: embryological basis and clinical significance. Rom J Morphol Embryol 2007;48:155-9.

35. Suoranta H, Pietilä K. An aberrant origin of the inferior suprarenal arteries associated with renal agenesis. J Urol 1974;112:428-9.

36. Jyothsna P, Mohandas Rao K, Somayaji S, Ashwini L. Multiple vascular anomalies involving testicular, suprarenal arteries and lumbar veins. N Am J Med Sci 2012;4:154-6.

37. Vinitha G, Parthasarathy M. Anatomical variant origin of suprarenal arteries from coeliac trunk development, and its clinical significance. Int J Res Med Sci 2020;8:460-3.

38. Bordei P, St Antohe D, Sapte E, Iliescu D. Morphological aspects of the inferior suprarenal artery. Surg Radiol Anat 2003;25:24751.

39. Hureau J, Hidden G, Minh TT. The vascularization of the suprarenal glands. Anat Clin 1980;2:127-46.

40. Hagopian AC. An abnormal inferior suprarenal artery. Yale J Biol Med 1953;26:78-9.

41. Rossi P, Passariello R, Simonetti G, Rovighi L, Crecco M. Arterious and venous system of the adrenal glands: anatomical considerations. Ann Radiol (Paris) 1979;22:372-7.

42. Xu R, Zhu Z, Tang W, Zhou Q, Zeng S. Zone-specific reference ranges of fetal adrenal artery Doppler indices: a longitudinal study. BMC Pregnancy Childbirth 2020;20:774.

43. Miekoś E. Anatomical basis of radiodiagnosis of the adrenal gland. Int Urol Nephrol 1979;11:193-200.

44. Mazza E. [Anatomical research on adrenal arteries in humans]. Minerva Chir 1954;9:175-81. Italian.

45. Levi G. [Variations of the adrenal and renal arteries studied with the serial statistical method]. Arch Ital Anat Embriol 1909;8:35-71. Italian.

46. Felix W. Mesonephric arteries (aa mesonephricae). In: Keibel LF, Mall FP, editors. Manual of Human Embryology. Philadelphia: Lippincott; 1912. p.820-5.

47. Hochstetter F. [Contributions to the development history of the vein system of the amniotics. III. Mammal]. Morp Jb 1893;20:543-648. German.

48. Abe H. [First of the evolution of the angiosistemo de la reno $\mathrm{c}^{\wedge} \mathrm{e}$ ham- steroj]. Kaibogaku Zasshi 1956;36:677-99. Esperanto.

49. Salama J, Folio P, Chevrel JP. [Reconstruction of the metanephros of a human embryo of 20 millimeters. Study of the origin of the renal artery]. Bull Assoc Anat (Nancy) 1982;66:397-406. French.

50. Isogai S, Horiguchi M, Hitomi J. The para-aortic ridge plays a key role in the formation of the renal, adrenal and gonadal vascular systems. J Anat 2010;216:656-70.

51. Hinata N, Suzuki R, Ishizawa A, Miyake H, Rodriguez-Vazquez JF, Murakami G, Fujisawa M. Fetal development of the mesonephric artery in humans with reference to replacement by the adrenal and renal arteries. Ann Anat 2015;202:8-17.

52. Turyna R, Kachlik D, Feyreisl J, Stingl J, Baca V. Anterior retroperitoneal rami: until now unnamed direct branches of the abdominal aorta. Clin Anat 2014;27:894-9.

53. Gerhardt H, Golding M, Fruttiger M, Ruhrberg C, Lundkvist A, Abramsson A, Jeltsch M, Mitchell C, Alitalo K, Shima D, Betsholtz C. VEGF guides angiogenic sprouting utilizing endothelial tip cell filopodia. J Cell Biol 2003;161:1163-77.

54. Ucuzian AA, Gassman AA, East AT, Greisler HP. Molecular mediators of angiogenesis. J Burn Care Res 2010;31:158-75.

55. Djonov VG, Galli AB, Burri PH. Intussusceptive arborization contributes to vascular tree formation in the chick chorioallantoic membrane. Anat Embryol (Berl) 2000;202:347-57. 